\title{
Expression and cellular localization of TSC-22 in normal salivary glands and salivary gland tumors: Implications for tumor cell differentiation
}

\author{
YUTAKA DOI $^{1 *}$, HITOSHI KAWAMATA ${ }^{1 *}$, YUKO ONO ${ }^{2}$, \\ TAKAHIRO FUJIMORI $^{2}$ and YUTAKA IMAI ${ }^{1}$
}

Departments of ${ }^{1}$ Oral and Maxillofacial Surgery and ${ }^{2}$ Surgical and Molecular Pathology, Dokkyo Medical University School of Medicine, Tochigi 321-0293, Japan

Received October 5, 2007; Accepted November 12, 2007

\begin{abstract}
TGF- $ß$-stimulated clone-22 (TSC-22) was reported to be a differentiation-inducing factor which negatively regulates the growth of salivary gland cancer cells. In the present study, we examined the expression of TSC-22 in salivary gland tumors by immunohistochemistry. In pleomorphic adenoma (PA), most of the sparse myoepitheliallike tumor cells, which are considered as the differentiated cells because they produce extracellular matrix, expressed TSC-22. However, only a limited number of cases of the solid myoepithelial-like tumor cells in $\mathrm{PA}$, which are considered as the growing cells, expressed TSC-22. In adenoid cystic carcinoma (ACC), inner ductal cells in the tubular structure, strongly expressed TSC-22, though the outer myoepithelial-like tumor cells did not express TSC-22. In the cribriform structure, myoepithelial-like tumor cells did not express TSC-22. However, a small ductal structure in the micro-cyst wall strongly expressed TSC-22. Sparse type myoepithelial-like tumor cells in ACC also expressed TSC-22. In mucoepidermoid carcinoma, epidermoid tumor cells and mucous-producing tumor cells in mucoepidermoid carcinoma frequently expressed TSC-22. Thus, the expression of TSC-22 was frequently observed in the cells with differentiatedphenotypes, although rarely in the cells with growing potentials. These results suggest that TSC-22 may play an important role in maintaining the differentiated phenotype in salivary gland tumors.
\end{abstract}

Correspondence to: Dr Hitoshi Kawamata, Department of Oral and Maxillofacial Surgery, Dokkyo Medical University School of Medicine, 880 Kitakobayashi, Mibu, Shimo-Tsuga, Tochigi, Japan E-mail: h-kawama@dokkyomed.ac.jp

${ }^{*}$ Contributed equally

Key words: TGF- $\beta$, TGF-ß-stimulated clone-22, salivary gland tumor, differentiation

\section{Introduction}

TGF- 3 -stimulated clone-22 (TSC-22) was originally reported as a TGF- $\beta$-inducible gene in mouse osteoblastic cells, MCT3T3E1 (1). Subsequently, rat TSC-22 (2) was isolated as a follicle-stimulating hormone inducible gene. Then we cloned human TSC-22 cDNA as a differentiation-inducing agent (vesnarinone)-inducible gene in a human salivary gland cancer cell line (3). At the same time, some other laboratories released the cDNA sequence for human TSC-22 $(4,5)$. Chicken TSC-22 cDNA (GenBank ${ }^{\mathrm{TM}}$ ) and a Drosophila gene (6), shortsighted, which had homology to mammalian TSC-22 genes were also isolated. TSC-22 was reported to be up-regulated by many different stimuli such as TPA, choleratoxin, dexamethasone (1), follicle-stimulating hormone (2), tumor necrosis factor- $\alpha$, interferon- $\gamma$, interleukin-1ß, lipopolysaccaride (4), progesterone (7) and epidermal growth factor (8).

We have been investigating the function of TSC-22 and have shown that TSC-22 negatively regulates the growth of salivary gland cancer cells $(3,9)$. We have also clarified that the TSC-22 protein is localized in the cytoplasm (10) and that overexpression of the TSC-22 protein enhances the chemo$(10,11)$ and radiation sensitivity (12) of salivary gland cancer cells in vitro and in vivo via the induction of apoptosis. Moreover, we demonstrated that the nuclear translocation of the TSC-22 protein from the cytoplasm is a key step in the induction of apoptosis in salivary gland cancer cells $(13,14)$. Recently, we isolated human TSC-22 genomic DNA and analyzed the structure of the human TSC-22 gene and the transcriptional regulation of the TSC-22 gene by several differentiation-inducing drugs (15). Thus, TSC-22 can be a molecular target for apoptosis-inducing therapy or differentiation-inducing therapy in salivary gland cancer (16).

In order to use the TSC-22 protein as a molecular target for therapy, it is important to detect the expression and cellular localization of TSC-22 in normal salivary glands and in salivary gland tumors. However, there have been no previous reports in which the expression and cellular localization of TSC-22 in normal salivary glands and salivary gland tumors were examined. We demonstrated that the antibody, which was previously produced in our laboratory $(3,9)$, worked well 
in immunohistochemistry on formalin-fixed, paraffinembedded tissues. In the present study, we examined the expression and cellular localization of TSC-22 in normal salivary glands, normal oral mucosa and salivary gland tumors by immunohistochemistry. We also analyzed the relation of the expression and cellular localization of TSC-22 in the tumor cells with the cellular-differentiation in salivary gland tumors.

\section{Materials and methods}

Patients and histopathological diagnosis. Thirty-seven cases of primary salivary gland tumors were examined in this study. Each tumor was surgically resected in our hospital from 1996 to 2005. The tumors did not receive any previous radiation therapy or chemotherapy. Normal salivary gland tissues and normal oral mucosal tissues, which were obtained during the surgical procedures for another disease, were also included in this study. All of the tissues were formalin-fixed and paraffinembedded. Sections ( $4-\mu \mathrm{m}$ thick) were stained with hematoxylin and eosin for a histopathological diagnosis. Salivary gland tumors were diagnosed and classified by two experienced surgical pathologists (Y.O. and T.F.) according to the recent edition (2005) of World Health Organization Classification of Tumors, Pathology and Genetics. Head and Neck Tumors (17).

Immunohistochemical staining. Sections (4- $\mu \mathrm{m}$ thick) were mounted on silane-coated glass slides, deparaffinized and rinsed. After antigen retrieval by microwave treatment in citric acid buffer ( $\mathrm{pH} 6.0$ ) at $95^{\circ} \mathrm{C}$ for $10 \mathrm{~min}$, the sections were immersed in $0.3 \%$ hydrogen peroxide in order to block endogenous peroxidase activity. Subsequently, the sections were reacted with or without the anti-TSC-22 primary antibody for $1 \mathrm{~h}$ at room temperature. The anti-TSC-22 antibody was produced in our laboratory $(3,8)$. In brief, recombinant Glutathione-S-transferase (GST)-TSC-22 fusion protein was produced in Escherichia coli. MC1061 recA-, which was transformed by $p G E X 4 T-2-T S C-22$ and was purified with a glutathione-Sepharose column. This purified protein was used for the generation of the antibody. GSTTSC-22 fusion protein $(300 \mu \mathrm{g})$ in incomplete adjuvant was injected into the rabbit. Two weeks after initial immunization, $300 \mu \mathrm{g}$ of GST-TSC-22 fusion protein in incomplete adjuvant was injected and the boosting was repeated every 2 weeks for 8 weeks. Serum obtained from the rabbit was tested for immunoreactivity against the purified GST-TSC-22 protein by an enzyme-linked immunosorbent assay. Subsequently, the anti-GST-TSC-22 serum was precipitated in $50 \%$ ammonium sulfate twice and the anti-GST antibody was removed by GST-conjugated Sepharose-4B column. The anti-TSC-22 antibody was further purified by a GST-TSC22-conjugated Sepharose-4B column. We confirmed that the antibody was suitable for Western blotting (9) and immunohistochemistry (unpublished observation). The sections were then incubated with the biotinylated secondary antibody in an LSAB kit (Dako, Carpinteria, CA) for $15 \mathrm{~min}$ at room temperature. After washing with cold phosphate-buffered saline, streptavidin-peroxidase solution in the LSAB kit was applied for $20 \mathrm{~min}$. The sections were washed in cold phosphate-buffered saline and were then allowed to react with
Table I. Expression of TSC-22 in normal salivary glands and other normal oral tissues.

Type of cells and tissues Expression of TSC-22a

Mucous acinus cells

Serous acinus cells

Myoepithelial cells

Salivary duct cells

Stratified squamous cells

Fibroblasts

Extracellular matrix

Striated muscle

Endothelial cells

Fat cells

Lymphocytes

Plasma cells

Neutrophils

Neuronal cells

Neuronal fiber

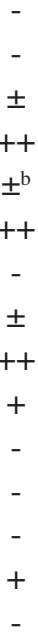

${ }^{\text {a }}$, negative; \pm , faintly positive; + , positive; ++ , strongly positive. ${ }^{b}$ Faintly positive only in the basal cells.

3,3'-diaminobenzidine tetrahydrochloride solution and $0.03 \%$ hydrogen peroxide for $3 \mathrm{~min}$ at room temperature. The sections were finally counterstained with hematoxylin. When we replaced the primary antibody with phosphate-buffered saline, the clear staining in all of the cells had completely disappeared.

Evaluation of the immunohistochemical staining. The evaluation of the immunohistochemistry was performed by two oral surgeons (Y.D. and H.K.) and one pathologist (Y.O.). The status of the TSC-22 staining was evaluated based on the staining intensity. Intensity was judged as strongly positive $(++)$, positive $(+)$, faintly positive $( \pm)$, or negative (-). We also determined the positive cell types (duct-like cells, acinus-like cells, myoepithelial-like cells and epidermoid cells) in the tumors. Moreover, we examined the cellular localization of TSC-22 in the positive cells.

\section{Results}

Expression of TSC-22 in normal salivary glands and other normal oral tissues. The expression of TSC-22 in normal oral tissues including salivary glands was examined (Fig. 1) and the results are summarized in Table I. TSC-22 was strongly expressed in salivary duct cells (Fig. 1A and F). Salivary duct cells were divided into three types of cells, intercalated duct cells, striated duct cells and excretory duct cells. All types of salivary duct cells were strongly positive for TSC-22. However, serous acinus cells (Fig. 1A) and mucous acinus cells (Fig. 1B) were completely negative for TSC-22. Myoepithelial cells in mucous glands were faintly positive for TSC-22 (Fig. 1B). Fatty degeneration (or fatty differentiation) was observed in the serous glands and the fat cells were positive for TSC-22 (Fig. 1A). We also examined 

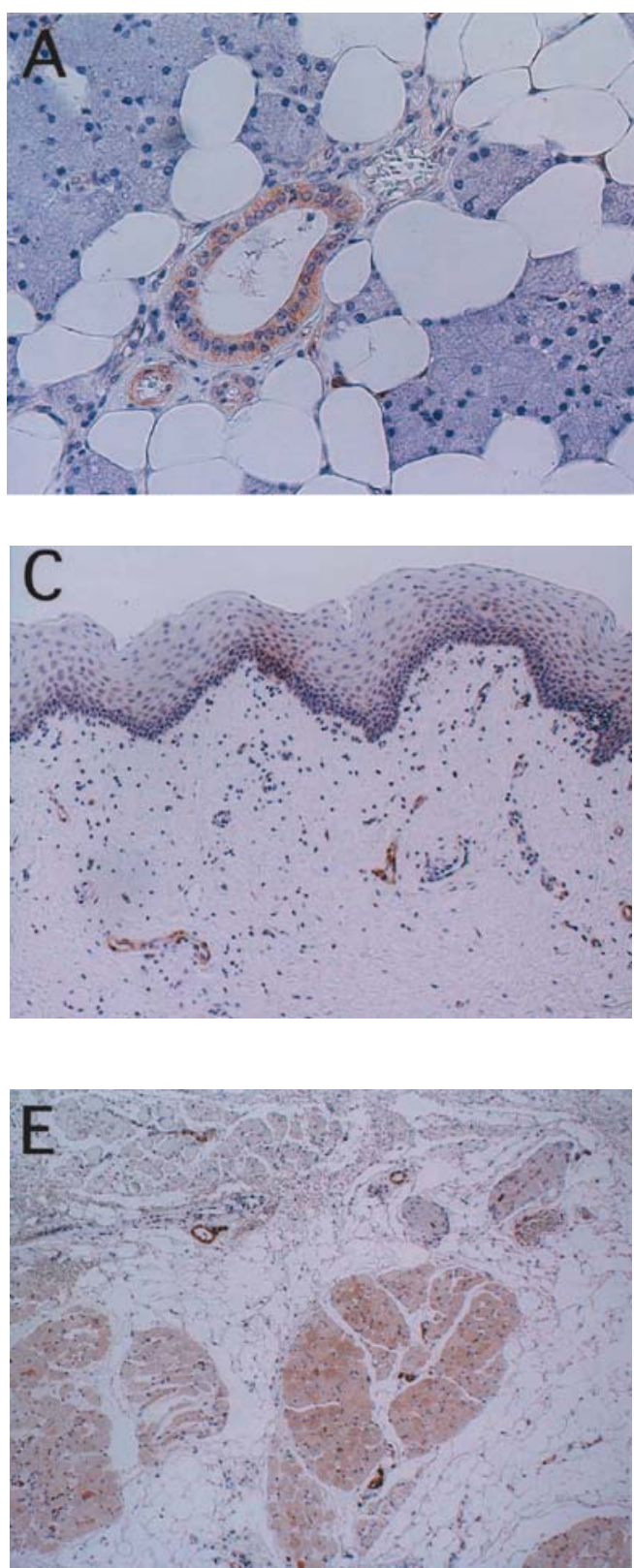
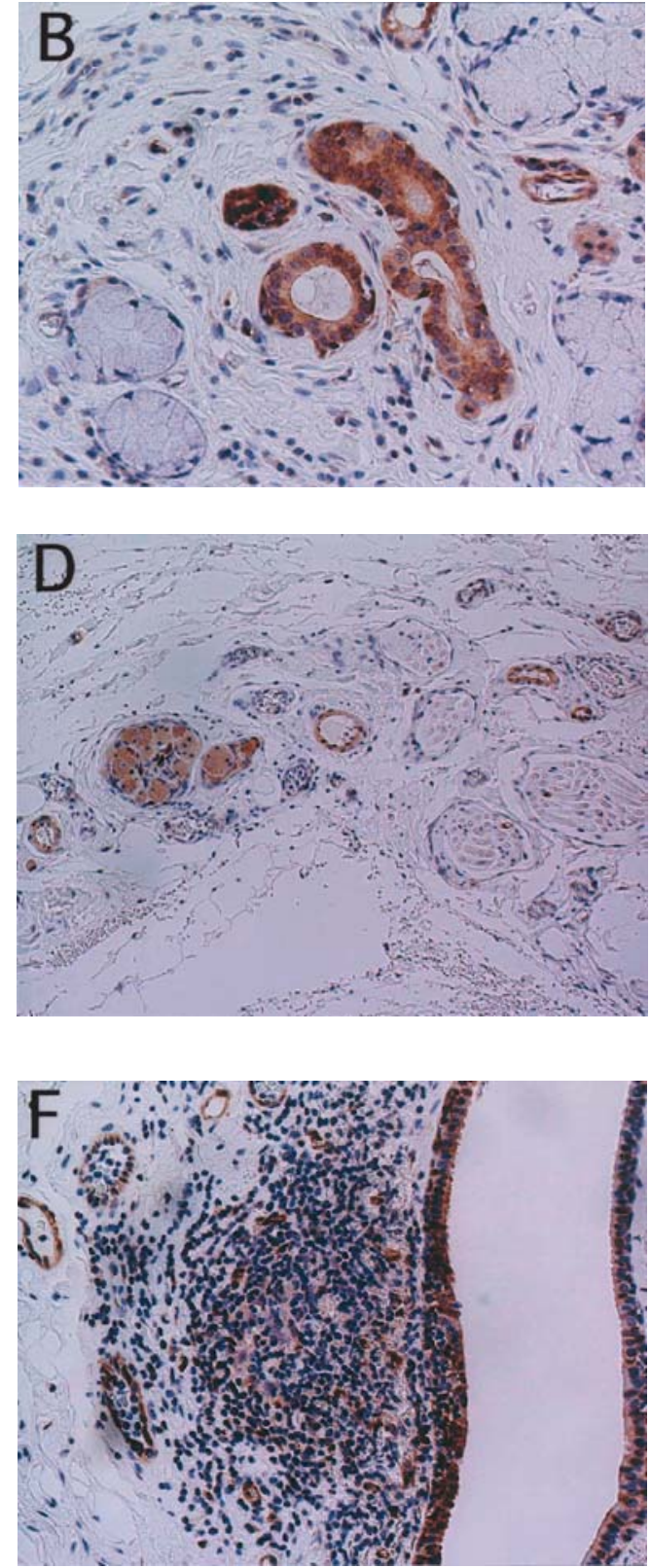

Figure 1. Expression of TSC-22 in normal salivary glands and other normal oral tissues. TSC-22 was strongly expressed in salivary duct cells (A, B and F). Serous acinus cells (A) and mucous acinus cells (B) were completely negative for TSC-22. Myoepithelial cells in the mucous glands were faintly positive for TSC-22 (B). Fat cells in the salivary gland were positive for TSC-22 (A). In other normal oral tissues, fibroblasts (C and F) and endothelial cells (A and B and D-F) were strongly positive for TSC-22. In the stratified squamous cells, only basal cells were faintly positive for TSC-22 (C). Neuronal cells were positive, though neuronal fibers were negative (D). Striated muscle (E) was faintly positive, although extracellular matrix (C-E) and infiltrated lymphocytes, plasma cells and neutrophils (F) were negative for TSC-22.

the expression of TSC-22 in salivary glands with inflammation. The expression pattern of TSC-22 in the inflammatory salivary glands was the same as that in the normal salivary glands (data not shown).

In other normal oral tissues, fibroblasts (Fig. 1C and F) and endothelial cells (Fig. 1A and B and D-F) were strongly positive for TSC-22. In the stratified squamous cells, only basal cells were faintly positive for TSC-22 (Fig. 1C). Neuronal cells were positive, though the neuronal fibers were negative (Fig. 1D). Striated muscle (Fig. 1E) was faintly positive, although the extracellular matrix (Fig. 1C-E), infiltrated lymphocytes, plasma cells and neutrophils (Fig. 1F) were negative for TSC-22.
In our previous study, we demonstrated that TSC-22 was clearly localized in the cytoplasm (13). Therefore, we attempted to detect the cellular localization of TSC-22 in the tissues. In most of the normal cells, TSC-22 was immunohistochemically localized in the cytoplasm (Fig. 1).

Expression of TSC-22 in benign salivary gland tumors. The expression of TSC-22 in 21 benign salivary gland tumors [20 cases of pleomorphic adenoma (PA) and 1 case of myoepithelioma] was examined (Fig. 2 and Table II). The original sites of the tumors are shown in Table II.

In PA, myoepithelial-like tumor cells were divided into two types, sparse and solid. Sparse myoepithelial-like tumor 

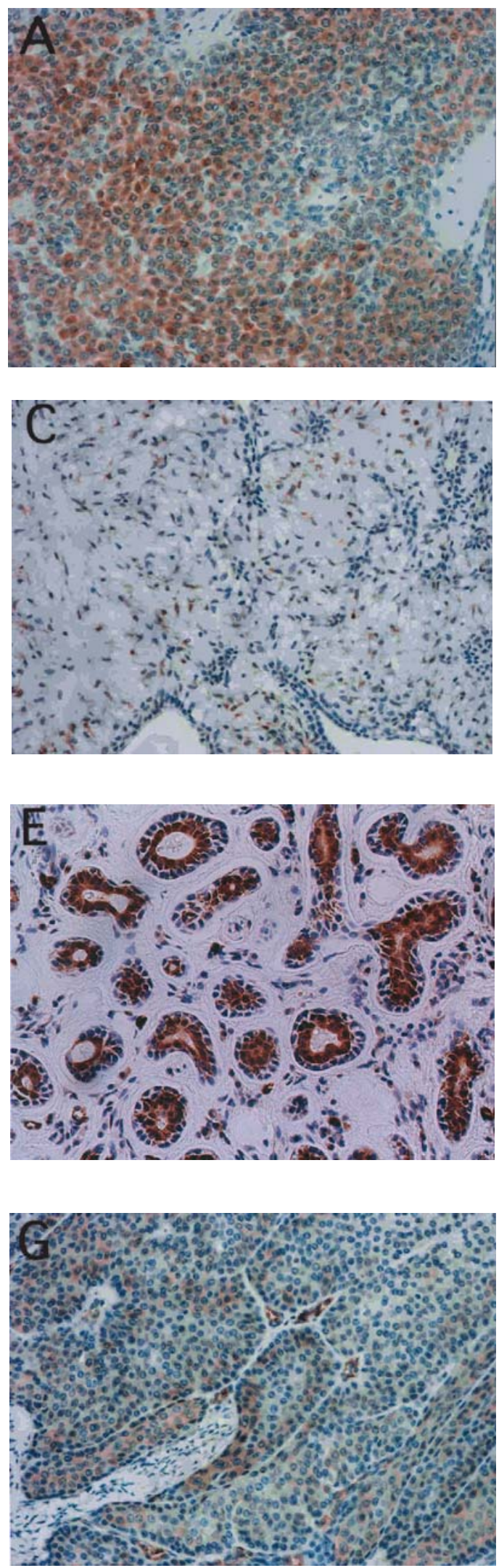
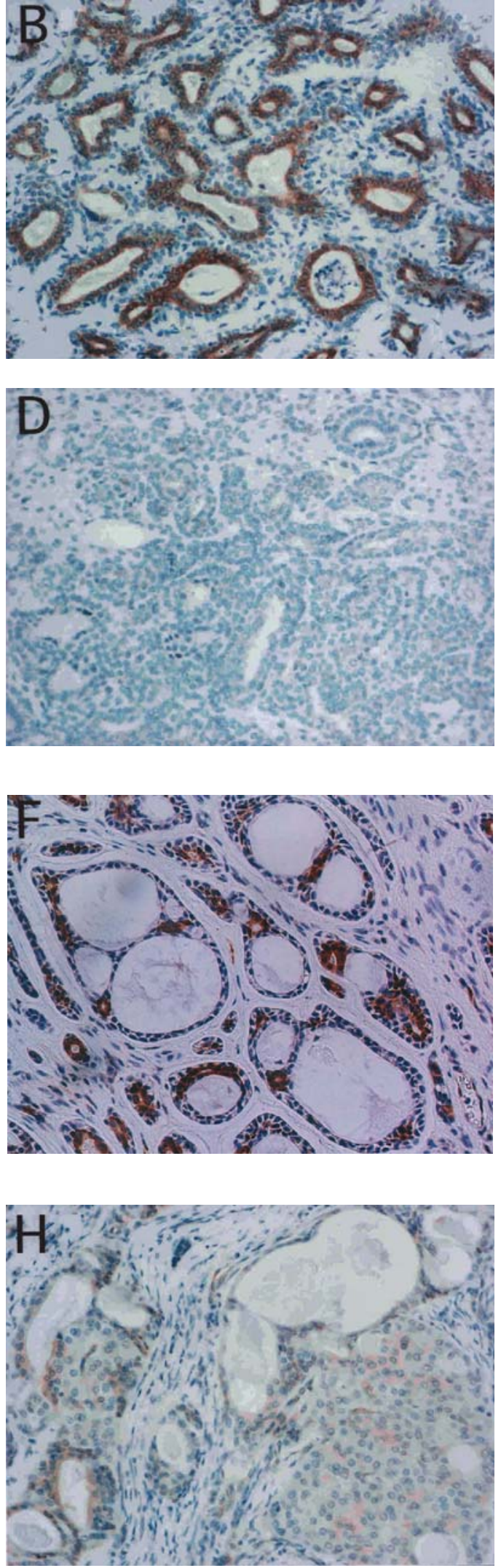

Figure 2. Expression of TSC-22 in salivary gland tumors. In pleomorphic adenoma, only a limited number of cases of the solid myoepithelial-like tumor cells expressed TSC-22 (A). However, most of the solid myoepithelial-like tumor cells did not express TSC-22 (B). When the solid myoepithelial-like tumor cells showed ductal differentiation, such differentiated cells strongly reacted to the TSC-22 antibody (B). Most of the sparse myoepithelial-like tumor cells expressed TSC-22 (C). In a few cases, the solid myoepithelial-like tumor cells and the ductal differentiated cells did not express TSC-22 (D). In adenoid cystic carcinoma, inner duct-like tumor cells in the tubular structure strongly expressed TSC-22, though the outer myoepithelial-like tumor cells did not express TSC-22 (E). In the cribriform structure, myoepithelial-like tumor cells, which were major components of the micro-cyst wall, did not express TSC-22, although the small ductal structure in the micro-cyst wall strongly expressed TSC-22 (F). In mucoepidermoid carcinoma, epidermoid cells (G) and mucous-producing tumor cells (H) expressed TSC-22. 
Table II. Expression of TSC-22 in benign salivary gland tumors.

\begin{tabular}{|c|c|c|c|c|c|c|}
\hline \multirow[t]{3}{*}{ No. } & \multirow{3}{*}{$\begin{array}{l}\text { Type of } \\
\text { tumors }^{\mathrm{a}}\end{array}$} & \multirow[t]{3}{*}{ Site ${ }^{b}$} & \multicolumn{4}{|c|}{ Expression of TSC-22c } \\
\hline & & & \multicolumn{2}{|c|}{ Myoepitheliall $^{\mathrm{d}}$} & \multirow[t]{2}{*}{ Duct } & \multirow[t]{2}{*}{ Others } \\
\hline & & & Sparse & Solid & & \\
\hline 1 & PA & Submand & + & - & - & NI \\
\hline 2 & PA & Palate & ++ & - & + & NI \\
\hline 3 & PA & Palate & + & - & ++ & NI \\
\hline 4 & PA & Parotid & + & - & + & NI \\
\hline 5 & PA & Buccal & - & - & ++ & NI \\
\hline 6 & PA & Palate & - & - & ++ & NI \\
\hline 7 & PA & Parotid & + & - & NI & NI \\
\hline 8 & PA & Palate & + & + & NI & NI \\
\hline 9 & PA & Sublingual & $\mathrm{NI}$ & - & + & NI \\
\hline 10 & PA & Parotid & + & - & NI & NI \\
\hline 11 & PA & Palate & ++ & - & ++ & NI \\
\hline 12 & PA & Parotid & ++ & + & ++ & NI \\
\hline 13 & PA & Lip & + & - & ++ & NI \\
\hline 14 & PA & Palate & + & + & NI & NI \\
\hline 15 & PA & Palate & - & - & - & NI \\
\hline 16 & PA & Palate & - & + & NI & e \\
\hline 17 & PA & Palate & + & - & ++ & NI \\
\hline 18 & PA & Palate & - & + & NI & NI \\
\hline 19 & PA & Submand & + & - & + & NI \\
\hline 20 & PA & Parotid & + & - & + & NI \\
\hline 21 & $\mathrm{ME}$ & Lip & - & - & NI & NI \\
\hline
\end{tabular}

aPA, pleomorphic adenoma; ME, myoepithelioma. 'bSubmand, submandibular gland; parotid, parotid gland; sublingual, sublingual gland. ${ }^{{ }^{c}++}+$, strongly positive; +, positive; -, negative; NI, cells were not identified in the tumor. ${ }^{\mathrm{d}}$ Myoepithelial-like cells were divided into two types, sparse and solid. Sparse myoepithelial-like cells were considered as the differentiated cells which could produce extracellular matrix. Solid myoepithelial-like cells were considered as the growing cells. ${ }^{e}$ Negative in mucin-producing cells.

cells were considered as the differentiated cells which could produce extracellular matrix. Solid myoepithelial-like tumor cells were considered as growing cells. We previously examined the expression of $\mathrm{Ki}-67$ as a proliferation marker on PA. Some of the solid myoepithelial cells expressed Ki-67, although sparse myoepithelial cells did not express Ki-67 (unpublished observation). Only a limited number of cases of the solid myoepithelial-like tumor cells expressed TSC-22 (Tables II and IV, Fig. 2A), however, 14 out of the 19 the solid myoepithelial-like tumor cells did not express TSC-22 ( $<<0.0001$, Chi-square test) (Tables II and IV, Fig. 2B). Notably, when the solid myoepithelial-like tumor cells showed ductal differentiation, such differentiated cells strongly reacted to the TSC-22 antibody (Fig. 2B). On the other hand, most of the sparse myoepithelial-like tumor cells expressed TSC-22 (Tables II and IV, Fig. 2C). In a few cases, the solid myoepithelial-like tumor cells and the ductal differentiated cells did not express TSC-22 (Tables II and IV, Fig. 2D). In myoepithelioma, TSC-22 was not expressed in the sparse and solid type myoepithelial-like tumor cells (Table II).
Expression of TSC-22 in malignant salivary gland tumors. The expression of TSC-22 in 16 malignant salivary gland tumors [ 8 cases of ACC (adenoid cystic carcinoma), 5 cases of mucoepidermoid carcinoma (MEC), 1 case of carcinoma ex pleomorphic adenoma (Ca-ex-PA), 1 case of polymorphous low-grade adenocarcinoma and 1 case of clear cell carcinoma] were examined (Fig. 2 and Table III). The original sites of the tumors are shown in Table III.

In ACC, the staining pattern of TSC-22 was quite characteristic (Fig. 2E and F and Table III). In the tubular structure, the inner duct-like tumor cells strongly expressed TSC-22, though the outer myoepithelial-like tumor cells did not express TSC-22 (Fig. 2E). In the cribriform structure, myoepithelial-like tumor cells, which were major components of the micro-cyst wall, did not express TSC-22 (Fig. 2F). However, the small ductal structure in the micro-cyst wall strongly expressed TSC-22 (Fig. 2F). Sparse type myoepithelial-like tumor cells were found in 3 of the 8 ACC and all of these differentiated cells also expressed TSC-22 (Table III).

In MEC, epidermoid cells in all 5 cases expressed TSC-22 (Fig. 2G and Table III). Furthermore, mucous-producing 
Table III. Expression of TSC-22 in malignant salivary gland tumors.

\begin{tabular}{|c|c|c|c|c|c|c|c|}
\hline \multirow[t]{3}{*}{ No. } & \multirow{3}{*}{$\begin{array}{l}\text { Type of } \\
\text { tumors }^{\mathrm{a}}\end{array}$} & \multirow[t]{3}{*}{ Site $^{b}$} & \multicolumn{5}{|c|}{ Expression of TSC- $22^{c}$} \\
\hline & & & \multicolumn{2}{|c|}{ Myoepithelial $^{\mathrm{d}}$} & \multirow[t]{2}{*}{ Duct } & \multicolumn{2}{|c|}{ Mucous squamous } \\
\hline & & & Sparse & Solid & & & \\
\hline 22 & $\mathrm{ACC}$ & Sublingual & NI & - & ++ & NI & NI \\
\hline 23 & $\mathrm{ACC}$ & Submand & NI & - & ++ & NI & NI \\
\hline 24 & $\mathrm{ACC}$ & Parotid & NI & - & ++ & NI & NI \\
\hline 25 & $\mathrm{ACC}$ & Palate & + & - & + & NI & NI \\
\hline 26 & $\mathrm{ACC}$ & Submand & NI & - & ++ & NI & NI \\
\hline 27 & $\mathrm{ACC}$ & Buccal & NI & - & ++ & NI & NI \\
\hline 28 & ACC & Submand & + & - & ++ & NI & NI \\
\hline 29 & ACC & Palate & + & - & NI & NI & NI \\
\hline 30 & MEC & Palate & NI & NI & NI & - & + \\
\hline 31 & MEC & Palate & NI & NI & NI & - & + \\
\hline 32 & MEC & Tongue & NI & NI & NI & + & + \\
\hline 33 & MEC & Oral floor & NI & NI & NI & + & + \\
\hline 34 & MEC & Mandible & NI & NI & NI & + & + \\
\hline 35 & PLGA & Palate & NI & - & - & - & - \\
\hline 36 & Ca-ex-PA & Palate & + & - & ++ & NI & NI \\
\hline 37 & $\mathrm{CCC}$ & Tongue & NI & NI & NI & NI & NI \\
\hline
\end{tabular}

${ }^{\text {aACC}}$, adenoid cystic carcinoma; MEC, mucoepidermoid carcinoma; PLGA, polymorphous low-grade adenocarcinoma; Ca-ex-PA, carcinoma

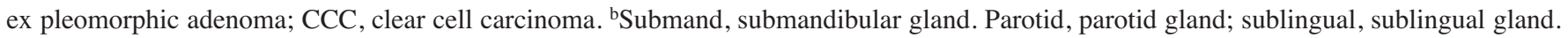
${ }^{c_{+}+}$, strongly positive; +, positive; -, negative; NI, cells were not identified in the tumor. ${ }^{\mathrm{d}}$ Myoepithelial-like cells were divided into two types, sparse and solid. Sparse myoepithelial-like cells were considered as the differentiated cells which could produce extracellular matrix. Solid myoepithelial-like cells were considered as growing cells.

Table IV. Summary of the expression of TSC-22 in pleomorphic adenoma, adenoid cystic carcinoma and mucoepidermoid carcinoma.

Type of tumors ${ }^{\mathrm{a}}$

Percentage of the expression of TSC-22 (positive cases/total cases) ${ }^{\mathrm{b}}$

\begin{tabular}{|c|c|c|c|c|c|}
\hline & \multicolumn{2}{|c|}{ Myoepithelialc } & \multirow[t]{2}{*}{ Duct } & \multirow[t]{2}{*}{ Squamous } & \multirow[t]{2}{*}{ Mucin } \\
\hline & Sparse & Solid & & & \\
\hline PA & $73 \%(14 / 19)^{\mathrm{d}}$ & $25 \%(5 / 19)^{\mathrm{d}}$ & $86 \%(13 / 15)^{\mathrm{d}}$ & NI & NI \\
\hline $\mathrm{ACC}$ & $100 \%(3 / 3)$ & $0 \%(0 / 8)$ & $100 \%(7 / 7)$ & NI & NI \\
\hline MEC & NI & NI & NI & $60 \%(3 / 5)$ & $100 \%(5 / 5)$ \\
\hline
\end{tabular}

aPA, pleomorphic adenoma; ACC, adenoid cystic carcinoma; MEC, mucoepidermoid carcinoma. bNI, cells were not identified in the tumors. ${ }^{\mathrm{c}}$ Myoepithelial-like cells were divided into two types, sparse and solid. Sparse myoepithelial-like tumor cells were considered as the differentiated cells which could produce extracellular matrix. Solid myoepithelial-like cells were considered as growing cells. ${ }^{\mathrm{d}}$ Expression of TSC-22 in solid myoepithelial-like tumor cells was significantly decreased when compared to those in sparse myoepithelial-like tumor cells and duct-like tumor cells $(\mathrm{p}<0.0001$, Chi-square test).

tumor cells in 3 of the 5 cases of MEC expressed TSC-22 (Fig. 2H and Table III). In the Ca-ex-PA, sparse myoepithelial-like tumor cells and duct-like tumor cells expressed TSC-22, though solid myoepithelial-like tumor cells did not express TSC-22 (Table III). Such an expression pattern of TSC-22 in the Ca-ex-PA was quite similar to that in benign PAs (Tables II and III). None of the cell types in the polymorphous low-grade adenocarcinoma expressed
TSC-22 (Table III). In this study, the clear cell carcinoma composed of only clear cell carcinoma cells and such cells did not express TSC-22 (Table III).

Relationship of the expression of TSC-22 with the tumor cell types. As shown in Table IV, tumor cells which showed differentiated-phenotype, express TSC-22. For example, sparse myoepithelial-like tumor cells and duct-like tumor 
cells in PA, ACC and epidermoid tumor cells and mucousproducing tumor cells in MEC frequently expressed TSC-22 (Table IV). The percentage of the expression of TSC-22 in sparse myoepithelial-like tumor cells and duct-like tumor cells was significantly higher than that in solid myoepitheliallike tumor cells in PA and ACC (Table IV, $\mathrm{p}<0.0001$ ).

Relationship of the expression of TSC-22 with clinical outcome. We compared the expression pattern of TSC-22 with the clinical outcome in the patients with salivary gland tumors. However, we cannot find any relationship in the expression of TSC-22 with the clinical outcome in the patients with malignant and benign salivary gland tumors (data not shown). Nineteen patients in 20 PA were cured after complete surgical resection of the tumor. Only one patient of PA recurred as a malignant tumor after incomplete resection. Four patients in 8 ACC died due to metastatic disease.

\section{Discussion}

There are several reports of the functional or expression analyses for the TSC-22 gene, which is known to regulate the growth and differentiation in several cell types (1-7,9-16). However, only a few reports showed the immunohistochemical expression and localization of the TSC-22 protein on paraffin-embedded tissue sections $(18,19)$. The reason why there are only a few reports on the immunohistochemistry of TSC-22 is that the antibody, which can work on formalinfixed, paraffin-embedded tissue sections, is not commercially available. In our previous study (9), we produced a specific antibody for TSC-22 and demonstrated that the antibody can be used for Western blotting and ELISA. In this study, we showed that our specific antibody for TSC-22 clearly visualized the expression and localization of TSC-22 on formalin-fixed, paraffin-embedded tissue sections.

It is well known that salivary gland tumors consist of several tumor cell components, such as myoepithelial-like tumor cells, duct-like tumor cells, acinus-like tumor cells, epidermoid-like tumor cells, mucin-producing tumor cells and tumor cells with mesenchymal differentiation (17). There are several reports concerning the direction of differentiation in salivary gland tumors or the tumor stem cells of salivary gland tumors (20-33). Sato et al established a cultured salivary gland tumor cell line, HSG (21) and investigated the differentiation potentials of HSG cells (22-26). They reported that HSG cells maintained a phenotype with salivary intercalated duct cells, and could differentiate into several cell types, such as myoepithelial-like cells (22), acinus-like cells (22), squamous cell-like cells (23), chondrocyte-like cells (24), neuronal cell-like cells (25) and osteoblast-like cells (26). It was concluded that the HSG cells or transformed intercalated duct cells might be the tumor stem cells for several components of the salivary gland tumors. On the other hand, under the basis of the observation of histopathology of salivary gland tumors, Aigner et al (27) and several other pathologists (28-33) reported that myoepithelial-like tumor cells might be the tumor stem cells or procurer cells for several components in salivary gland tumors (22-28).

In this study, we demonstrated that in PA, TSC-22 was rarely positive in the solid myoepithelial-like tumor cells, which might be growing cells, however, TSC-22 was consistently positive in the sparse myoepithelial-like tumor cells, which might stop growing and start to produce extracellular matrix. Thus, the sparse myoepithelial-like tumor cells can be considered to be differentiated cells in the salivary gland tumors. Additionally, in PA and ACC, the cells, which lined the luminal surface of the ductal structure, strongly expressed TSC-22, though adjacent solid myoepithelial-like tumor cells were completely negative for TSC-22. These observations indicate that the TSC-22positive luminal cells (ductal cells) might be differentiated from the adjacent solid myoepithelial-like cells. Thus, the expression of TSC-22 was frequently observed in cells with differentiated-phenotypes, though rarely in the cells with growing potential. These observations are compatible with those of our previous reports, in which cultured salivary gland tumor cells were used for the experiments. Moreover, our results and interpretation may support the hypothesis proposed by Aigner and other pathologists, in which myoepithelial-like tumor cells were the tumor stem cells or procurer cells in salivary gland tumors.

We compared the expression pattern of TSC-22 with the clinical outcome in the patients with salivary gland tumors. However, in this experiment, it was hard to evaluate the role of TSC-22 in PA for predicting tumor recurrence. Moreover, there was no clear relationship between the expression pattern of TSC-22 and the metastatic potential of the ACC. Since salivary gland tumors consist of several tumor cell components and because the expression of TSC-22 in the tumor is very limited to the specific cells, it is hard to discuss the implications of TSC-22 expression with the clinical outcome of the patients. However, TSC-22 plays an important role in maintaining a differentiated phenotype, in other words, the reduction of malignancy, in salivary gland tumors. Although TSC-22 cannot be a predictive or prognostic marker for salivary grand tumors, we propose that TSC-22 is a key molecule in salivary gland differentiation and can be used as a molecular target for cancer differentiation therapy in salivary gland cancer. Thus, the analysis of the precise role of TSC-22 in tumor development and progression may pave the way to a novel differentiation therapy on solid tumors, including salivary gland tumor.

\section{Acknowledgements}

We are indebted to Chiaki Sato-Matsuyama, Ayako Shimizu, Takako Ohtsuki and Midori Matsuura-Katayama (Department of Surgical and Molecular Pathology, Dokkyo Medical University, School of Medicine) for their excellent technical assistance. This study was supported by a Grant-in-Aid for Scientific Research from The Ministry of Education, Culture, Sports, Science and Technology and Japan Society for the Promotion of Science and Research of the Seki Minato Foundation.

\section{References}

1. Shibanuma M, Kuroki T and Nose K: Isolation of a gene encoding a putative leucine zipper structure that is induced by transforming growth factor $\beta 1$ and other growth factors. J Biol Chem 267: 10219-10224, 1992. 
2. Hamil KG and Hall SH: Cloning of rat sertoli cell folliclestimulating hormone primary response complementary deoxyribonucleic acid regulation of TSC-22 gene expression. Endocrinology 134: 1205-1212, 1994.

3. Kawamata H, Nakashiro K, Uchida D, Hino S, Omotehara F, Yoshida $\mathrm{H}$ and Sato M: Induction of TSC-22 by treatment with a new anti-cancer drug, vesnarinone, in a human salivary cancer cell. Br J Cancer 77: 71-78, 1998.

4. Ohta S, Shimekake Y and Nagata K: Molecular cloning and characterization of a transcription factor for the C-type natriuretic peptide gene promoter. Eur J Biochem 242: 460-466, 1996.

5. Jay P, Ji JW, Marsollier C, Taviaux S, Berge-Lefranc JL and Berta P: Cloning of human homologue of the TGF- 3 -stimulated clone 22 gene. Biochem Biophys Res Commun 222: 821-826, 1996.

6. Treisman JE, Lai ZC and Rubin GM: Shortsighted acts in the decapentaplegic pathway in drosophila eye development and has homology to a mouse TGF- $\beta$-responsive gene. Development 121 : 2835-2845, 1995.

7. Kester HA, van der Leede BJM, van der Saag PT and van der Burg B: Novel progesterone target genes identified by an improved differential display technique suggest that progestininduced growth inhibition of breast cancer cells coincides with enhancement of differentiation. J Biol Chem 272: 16637-16643, 1997.

8. Trenkle T, Welsh J, Jung B, Mathieu-Dandu F and McClelland M: Non-stoichimetric reduced complexity probes for cDNA arrays. Nucleic Acids Res 26: 3883-3891, 1998.

9. Nakashiro K, Kawamata H, Hino S, Uchida D, Miwa Y, Hamano H, Omotehara F, Yoshida $\mathrm{H}$ and Sato M: Downreguration of TSC-22 (transforming growth factor B-stimulated clone 22) markedly enhances the growth of a human salivary gland cancer cell line in vitro and in vivo. Cancer Res 58: 549-555, 1998.

10. Uchida D, Kawamata H, Omotehara F, Miwa Y, Hino S, Nasima-Mila B, Yoshida $\mathrm{H}$ and Sato $\mathrm{M}$ : Overexpression of TSC-22 (TGF- 3 stimulated clone-22) markedly enhances 5fluorouracil-induced apoptosis in a human salivary gland cancer cell line. Lab Invest 80: 955-962, 2000.

11. Omotehara F, Uchida D, Hino S, Nasima-Mila B, Yoshida H, Sato $\mathrm{M}$ and Kawamata $\mathrm{H}$ : In vivo enhancement of chemosensitivity of human salivary gland cancer cells by overexpression of TGF- $\beta$-stimulated clone-22. Oncol Rep 7: 737-740, 2000.

12. Hino S, Kawamata H, Omotehara F, Uchida D, Miwa Y, Nasima-Mila B, Yoshida H, Sato $M$ and Fujimori T: Cytoplasmic TSC-22 (transforming growth factor- $\beta$-stimulated clone-22) markedly enhances the radiation sensitivity of salivary gland cancer cells. Biochem Biophys Res Commun 292: 957-963, 2002.

13. Hino S, Kawamata H, Uchida D, Omotehara F, Miwa Y, Nasima-Mila B, Yoshida H, Fujimori T and Sato M: Nuclear translocation of TSC-22 (TGF- $\beta$-stimulated clone-22) concomitant with apoptosis: TSC-22 as a putative transcriptional regulator. Biochem Biophys Res Commun 278: 659-664, 2000.

14. Hino S, Kawamata H, Omotehara F, Uchida D, Nasima-Mila B, Yoshida $\mathrm{H}$, Sato $\mathrm{M}$ and Fujimori T: Leucine zipper structure of TSC-22 (TGF- $\beta$-stimulated clone-22) markedly inhibits the anchorage-independent growth of salivary gland cancer cells. Oncol Rep 9: 371-374, 2002.

15. Uchida D, Omotehara F, Nakashiro K, Tateishi Y, Hino S, Nasima-Mila B, Fujimori T and Kawamata H: Posttranscriptional regulation of TSC-22 (TGF- 3 -stumulated clone-22) gene by TGF-ß1. Biochem Biophys Res Commun 305: 846-854, 2003.

16. Kawamata H, Fujimori T and Imai Y: TSC-22 (TGF- $\beta$ Stimulated Clone-22): A novel molecular target for differentiationinducing therapy in salivary gland cancer. Curr Cancer Drug Targets 4: 521-529, 2004.
17. Leon B, Johon WE, Peter R and David S: World Health Organization classification of tumors. Pathology and genetics. Head and neck tumors. IARC, Lyon, pp209-282, 2005.

18. Rentsch CA, Cecchini MG, Schwaninger R, Germann M, Markwalder R, Heller M, van der Pluijm G, Thalmann GN and Wetterwald A: Differential expression of TGF B-stimulated clone 22 in normal prostate and prostate cancer. Int J Cancer 15: 118: 899-906, 2006.

19. Shostak KO, Dmitrenko VV, Vudmaska MI, Naidenov VG, Beletskii AV, Malisheva TA, Semenova VM, Zozulya Yu P, Demotes-Mainara J and Kavsan VM: Patterns of expression of TSC-22 protein in astrocytic gliomas. Exp Oncol 27: 314-318, 2005.

20. Lewis RE: Histogenic classification of salivary tumors. Arch Pathol 92: 433-443, 1971

21. Shirasuna K, Sato M and Miyazaki T: A neoplastic epithelial duct cell line established from an irradiated human salivary gland. Cancer 48: 745-752, 1981.

22. Sato M, Azuma M, Hayashi Y, Yanagawa T and Yura Y: Azacytidine inductin of stable myoepithelial and acinar cells from a human salivary intercalated duct cell clone. Cancer Res 47: 4453-4459, 1987.

23. Azuma M, Kawamat H, Kasai Y, Nagamine S, Yoshida H, Yanagawa $\mathrm{T}$ and Sato $\mathrm{M}$ : Effects of retinoic acid on morphological features and biological markers of a neoplastic human salivary intercalated duct cell line in culture. Cancer Res 48: 7219-7225, 1988.

24. Azuma M, Kawamata H, Kasai Y, Yanagawa T and Sato M: Induction of cells with a choudrocyte-like phenotype by treatment with 1 alpha, 25-dihydroxyvitamin D3 in a human salivary acinar cell line. Cancer Res 49: 5435-5442, 1989.

25. Kawamata H, Azuma M, Yanagawa T, Yura Y, Yoshida H, Furumoto N and Sato M: Effect of dibutyryl cyclic adenosine 3', 5 '-monophosphate on morphological features and biological markers of human salivary myoepithelial cell line in culture: Cancer Invest 3: 111-127, 1992.

26. Sato M, Iga H, Yoshioka N, Fukui K, Kawamata H, Yoshida H, Hirota S and Kitamura Y: Emergence of osteoblast-like cells in a neoplastic human salivary cancer cell line after treatment with 22-oxa-1 alpha, 25-dihydroxyvitamin D3: Cancer Lett 115: 149-160, 1997.

27. Aigner T, Neureiter D, Volker U, Belke J and Kirchner T: Epithelial-mesenchymal transdifferentiation and extracellular matrix gene expression in pleomorphic adenoma of the parotid salivary gland. J Pathol 186: 178-185, 1998.

28. Dardick I, van Nostrand AW and Phillops MJ: Histogenesis of salivary gland pleomorphic adenoma (mixed tumor) with an evalution of the role of the myoepithelial cell. Hum Pathol 13: $62-75,1982$.

29. Robert AE, Carlos $\mathrm{CC}$ and Paul JH: Histogenesis of benign pleomorphic adenoma (mixed tumor) of the major salivary glands. Am J Surg Pathol 8: 803-820, 1984.

30. Hubner G, Klein HJ, Kleinsasser O and Schiefer HG: Role of myoepithlial cells in the development of salivary gland tumors. Cancer 27: 1255-1261, 1971 .

31. Regezi JA and Batsakis JG: Histogenesis of salivary gland neoplasms. Otolaryngol Clin North Am 10: 297-307, 1977.

32. Welsh RA and Mayer AT: Mixed tumors of human salivary glands: histogenesis. Arch Pathol 85: 433-447, 1968.

33. Margaritescu C, Raica M, Florescu M, Simionescu C, Surpateanu M, Jaubert F and Bogdan FI: The ultrastructural aspects of neoplastic myoepithelial cell in pleomorphic adenomas of salivary gland. J Cell Mol Med 8: 369-381, 2004. 